\title{
A Mechanism-Based Approach to Prevention of and Therapy for Fibromyalgia
}

\author{
Charles J. Vierck \\ Department of Neuroscience and Comprehensive Center for Pain Research, Colleges of Medicine and Dentistry, University of Florida, \\ P.O. Box 100444, 1600 S.W. Archer Road, Gainesville, FL 32610, USA
}

Correspondence should be addressed to Charles J. Vierck, vierck@mbi.ufl.edu

Received 15 May 2011; Accepted 6 July 2011

Academic Editor: Petra Schweinhardt

Copyright ( 12012 Charles J. Vierck. This is an open access article distributed under the Creative Commons Attribution License, which permits unrestricted use, distribution, and reproduction in any medium, provided the original work is properly cited.

\begin{abstract}
Fibromyalgia syndrome (FMS) is characterized by pain referred to deep tissues. Diagnosis and treatment of FMS are complicated by a variable coexistence with regional pain, fatigue, sleep disruption, difficulty with mentation, and depression. The widespread, deep pain of FMS can be a consequence of chronic psychological stress with autonomic dysregulation. Stress acts centrally to facilitate pain and acts peripherally, via sympathetic vasoconstriction, to establish painful muscular ischemia. FMS pain, with or without a coexistent regional pain condition, is stressful, setting up a vicious circle of reciprocal interaction. Also, stress interacts reciprocally with systems of control over depression, mentation, and sleep, establishing FMS as a multiple-system disorder. Thus, stress and the ischemic pain it generates are fundamental to the multiple disorders of FMS, and a therapeutic procedure that attenuates stress and peripheral vasoconstriction should be highly beneficial for FMS. Physical exercise has been shown to counteract peripheral vasoconstriction and to attenuate stress, depression, and fatigue and improve mentation and sleep quality. Thus, exercise can interrupt the reciprocal interactions between psychological stress and each of the multiple-system disorders of FMS. The large literature supporting these conclusions indicates that exercise should be considered strongly as a first-line approach to FMS therapy.
\end{abstract}

\section{Mechanistic Base of FMS Prevention and Therapy}

Clinical diagnosis of fibromyalgia syndrome (FMS) has relied heavily upon tender point counts, a convenient evaluation of pain sensitivity that has come under scrutiny in terms of reliability and validity [1]. Tender point testing is designed to provide objective evidence for hypersensitivity to palpation of deep tissues, consistent with patient reports of ongoing pain referred to deep tissues. The location of ongoing pain changes over time but is widespread in the aggregate. The pain is chronic but is not always present. These features suggest that deep tissues are chronically sensitized and are easily brought to threshold for activation of nociceptors. Accordingly, tests of deep pressure sensitivity with control over the stimulus and thorough psychophysical evaluations reveal allodynia and hyperalgesia for stimulation of a muscle within the aggregate distribution of FMS pain. When muscular indentations are controlled in duration and force, FMS subjects report lower pain thresholds [2] and substantially more pain for suprathreshold stimulation than control subjects [2-8]. Repetitive stimulation at the threshold force for pain during a single indentation produces higher ratings by FMS subjects, compared to repetitive threshold stimulation for control subjects. Pain is longer in duration for FMS subjects following a series of repetitive muscular indentations. These observations [8] provide diagnostic verification of the ongoing deep muscular pain that brings FMS patients to the clinic.

FMS pain can arise from peripheral influences of the autonomic nervous system $[9,10]$ in response to aversive mood states (e.g., anxiety, fear, sorrow, and depression) that are referred to generally as mental suffering or distress. Distress activates the hypothalamopituitary axis (HPA) and sympathetic nervous system to generate physiological adaptations referred to as psychological stress reactions [11]. Stress, when chronic, results in cardiovascular dysfunction [12-16] with reduced peripheral blood flow as a result of vasoconstriction [17-19] and reduced endotheliumdependent vasodilatation $[20,21]$. Also, chronic stress 
produces mitochondrial damage and pathological changes in the vasculature that reduce blood flow [22]. Resting levels of peripheral vasoconstriction are particularly high for females, relative to males [23-29], and FMS primarily is a female pain disorder [10]. Consistent with a predisposition toward peripheral vasoconstriction, females are particularly susceptible to Raynaud's syndrome [30, 31], characterized by excessive cutaneous vasoconstriction and pain in response to ambient cold. Also, peripheral artery disease (PAD) with reduced peripheral blood flow is more prevalent for women $[32,33]$. Over time, reduced peripheral blood flow can lead to development of muscular ischemia $[34,35]$.

Phasic peripheral vasoconstriction, when robust, is painful, as demonstrated by the cold pressor test. Recordings of muscle nerve sympathetic activity (MSA) during ice water immersion of a hand or foot have shown that pain and MSA activity are highly correlated [36]. Similarly, acute muscular ischemia is painful, as evidenced by the submaximal effort tourniquet test [37]. Thus, when psychological stress and peripheral vasoconstriction become chronic and establish muscular ischemia, with sensitization of nociceptors $[38,39]$, muscular pain is easily evoked [9]. In turn, nociceptive input (e.g., from ischemic muscles) increases sympathetic vasoconstrictor outflow to muscles $[40,41]$, reinforcing the ischemia. Pain from vasoconstriction and muscular ischemia can explain the referral of FMS pain to deep tissues.

In addition to ongoing or spontaneous muscular pain, psychophysical testing of FMS individuals has revealed widespread cutaneous hyperalgesia [42]. A parsimonious explanation for this effect is that nociceptive input from deep tissues sensitizes spinal neurons having convergent input from the skin, resulting in cutaneous hyperalgesia within the distribution of deep FMS pain [43]. The most thoroughly studied form of central sensitization is temporal summation (windup), a form of central synaptic magnification that requires repetitive or tonic nociceptive input to central neurons [43]. This phenomenology has led to proposals that central sensitization underlies FMS pain [42] and also is responsible for the widespread cutaneous hyperalgesia that accompanies regional pain conditions [44]. However, central sensitization from nociceptive driving does not readily explain the widespread cutaneous hyperalgesia that accompanies regionally localized pain conditions [37, 45-59]. Spinal neurons supplying areas of cutaneous hypersensitivity can be located distant from a source of regional pain. For example, central nociceptive pathways from the foot and the face originate separately from the spinal cord and brain stem, with different thalamic relays to the cerebral cortex. In spite of this separation, temporomandibular pain is associated with enhanced sensitivity to nociceptive stimulation of the foot [56], and patients with irritable bowel syndrome are hypersensitive to stimulation of the face [54] (J. Riley, A. Mauderli, and C. Vierck, unpublished observations). Thus, a source of facilitation other than direct synaptic driving by nociceptive input (e.g., temporal summation) is required to generate widespread cutaneous hyperalgesia from a regional source of pain. The stress and autonomic dysregulation that accompany localized chronic pain can account for widespread hyperalgesia [58, 60-66, 66-68] and development of FMS pain after onset of a regional pain condition [50].

\section{Status of FMS Muscles}

The relationships outlined above indicate that a primary objective of FMS prevention and therapy should be to reduce sympathetic vasoconstriction and muscular ischemia, resulting in a loss or reduction of widespread deep pain and hyperalgesia. Prevention applies to the development of FMS in association with chronic stress (e.g., from a regional pain condition), and reducing stress and increasing blood supply to peripheral tissues should be therapeutic if FMS has developed. The need to increase blood flow to peripheral tissues is strongly supported by demonstrations of muscle pathophysiology among FMS patients. Microcirculation is deficient for FMS individuals, as indicated by reductions in capillary density, capillary permeability, and blood flow, resulting in low tissue oxygenation [69-73]. The normal increase in blood flow during dynamic and static exercise (hyperaemia) is attenuated for FMS subjects [74]. Intramuscular concentrations of pyruvate and lactate are increased for subjects with FMS and are negatively correlated with pressure pain thresholds (PPTs) for muscle [2]. Expression of genes that detect muscle metabolites signaling pain and fatigue is increased following exercise by FMS individuals [75]. The strength and endurance of FMS subjects is decreased and is associated with high ratings of exercise induced pain [76, 77]. During and following dynamic exercise, muscle tension of FMS subjects is increased [76]. Inflammatory activity is altered toward an overproduction of proinflammatory cytokines [77-82]. Mitochondrial dysfunction of FMS individuals has been described, with a CoQ ${ }_{10}$ deficiency in blood mononuclear cells, increased oxidative stress, and mitophagy [83]. Thus, peripheral pathology associated with chronically reduced blood flow to deep tissues clearly can be a factor in generation of FMS pain.

\section{Exercise Effects on Muscles}

Long-term programs of exercise have beneficial effects on stress and its effects on muscles of individuals with FMS and other conditions of ischemic muscular pain. Cardiovascular consequences of acute stress have been shown to be attenuated following a bout of exercise [17, 84-88]. For individuals with hypertension, a condition associated with chronic stress, exercise decreases sympathetic output to muscles [89] and decreases peripheral vascular resistance [90]. Thus, sympathetic activation by acute or chronic stress can be attenuated by exercise. Exercise promotes angiogenesis and attenuates symptoms of intermittent claudication and ischemic muscle pain associated with peripheral artery disease [91]. Muscular contraction induces secretion of vascular endothelial growth factor (VEGF), an essential contributor to capillary growth in skeletal muscles [92]. Accordingly, capillary density is increased by long-term exercise programs [93, 94]. Exercise increases expression of genes involved in mitochondrial biogenesis [95]. Also, 
oxygen consumption $\left(\mathrm{VO}_{2}\right)$ is increased during exercise, to meet increased energy needs, and it remains elevated for hours following exercise-particularly when the exercise is distributed in time [96]. Blood flow to an exercised muscle is increased [97-100], along with $\mathrm{VO}_{2}$ [101], with little generalization to uninvolved muscles, avoiding hypotension [102]. The increase in blood flow in proportion to the relative activity of different muscle groups is referred to as functional sympatholysis, which declines with age [103]. Also following exercise, there is generalized sympathoinhibition [104] and prevention or reversal of endothelial dysfunction $[105,106]$. Important functions of the endothelium that are enhanced by exercise include vasodilation, regulation of neovascular growth, and inflammatory control [105, 107].

\section{Temperature Regulation and Blood Flow to Muscles}

Control over blood flow to peripheral tissues is a fundamental component of temperature regulation. Cold environmental temperatures generate vasoconstriction, and warm temperatures elicit vasodilation, resulting in heat retention or loss, respectively [108]. The implications of temperature regulation for FMS are obvious. Individuals with FMS should stay warm, and exercise generates body heat. Studies of sauna heat therapy have revealed significant improvement in blood flow (endothelium-dependent dilation) [109-111] and reductions in FMS pain $[112,113]$. Exercise in warm water is an effective therapeutic procedure for FMS [114], with long-term reductions in pain [115]. Exercise in water is well tolerated by FMS individuals, as it limits stress on weight bearing joints and provides resistance in proportion to the speed of movements.

\section{Exercise Therapy for Distress and Depression}

In addition to widespread pain and hyperalgesia, FMS is associated with disrupted control over numerous physiological and psychological functions. Accordingly, there has been a shift in emphasis away from seeing FMS strictly as a pain disorder toward regarding it as a multisystems disorder [1, 116]. Symptoms frequently associated with FMS pain include sleep disruption, depression, fatigue, and altered mentation (fibrofog). Mechanistically, these multiple symptoms of FMS can be seen as products of FMS pain and the stress inevitably associated with pain. Sleep disruption, inactivity, and fatigue are predictable consequences of chronic pain [117] and stress [118-120]. Similarly, depression [118, 121, 122] and memory disturbances $[123,124]$ can result from chronic stress. Thus, FMS fundamentally is a disorder involving reciprocal interactions between pain and stress. Pain can result from or be enhanced by chronic stress $[49,66,125-$ $132]$, and pain produces stress [64, 133-137], which has widespread influences on biological systems $[11,62]$.

Mood disorders both elicit stress and are consequences of stress. Distress, the driving force for chronic psychological stress with HPA and sympathetic activation, is attenuated by exercise programs for individuals relatively free of autonomic dysregulation [138] or with hypertension [139] or chronic pain $[140,141]$. Depression, a mood disorder which often accompanies chronic pain, including FMS, is associated with autonomic dysregulation [142] and with cardiovascular disease [143]. Depression can evolve from chronic stress $[121,144,145]$ and from chronic pain $[146,147]$, and it is a risk factor for chronic pain [142, 148, 149]. Stress, chronic pain and depression frequently coexist and are considered to be reciprocally related [150], each facilitating the other. As depression increases, so do pain complaints, and as pain episodes increase in intensity, frequency, duration, or variety, depression becomes more likely [151]. Exercise can disrupt these interactions by reducing pain $[114,140,141,152-$ 156] and depression $[114,140,141,152,153,156-159]$. Conversely, depression occurs more frequently for sedentary individuals [160] or when a long-term program of exercise is interrupted for as little as 2 weeks [161].

\section{Stress, Exercise, and Mentation}

Psychological stress can either facilitate or interfere with learning and memory, depending upon the timing of HPA activation relative to the event to be learned or remembered, and the magnitude and duration of stress are critical variables $[124,162]$. While acute stress can be beneficial, chronic stress is detrimental to learning and memory. Activation of the HPA by psychological stress prominently involves the prefrontal cortex, amygdale, and hippocampus, with feedback regulation via corticosteroid receptors in these structures [123]. Chronic activation of corticosteroid receptors within the prefrontal cortex results in neuronal damage, impairing learning and memory $[163,164]$. The hippocampus is a component of the cerebral circuitry mediating psychological stress and is a crucial structure for memory consolidation. Stress reduces neurogenesis in the hippocampus $[165,166]$, impairing memory and contributing to the pathophysiology of depression [167]. Depression and cognitive decline are linked phenomena [168].

Beneficial effects of exercise on mentation have been documented thoroughly [169]. Large surveys have revealed an inverse relationship between cognitive decline (including Alzheimer's dementia) and levels of exercise. Prospective studies have similarly shown an inverse relationship between objective fitness measures and cognitive decline. The largest effect sizes were for executive functions such as planning, working memory, and multitasking. Investigations of exercise programs for individuals with dementia have revealed beneficial effects on cognitive tests, increased cerebral blood flow, and spared brain volume. A dose-response relationship pertains to exercise duration/intensity and quality of life for older individuals [170].

Laboratory animal experiments have revealed mechanisms for exercise effects on mentation [168]. In brief, exercise induces a cascade of growth factor signaling that enhances cognitive function and attenuates depression by stimulating neuroplasticity and neurogenesis and improving blood flow. The growth factors IGF-1, BDNF, and VEGF are increased peripherally and centrally by exercise. IGF-1 
increases BDNF signaling in response to exercise, enhancing neurogenesis and synaptic plasticity in the hippocampus and thereby facilitating learning and memory. Peripheral IGF1 and VEGF are necessary for exercise-induced prevention of peripheral risk factors for cognitive decline, such as hypertension, hyperglycemia and inflammation.

\section{Stress, Exercise, and Sleep}

Psychological stress, pain, and sleep disruption are reciprocally related. Stress increases pain sensitivity $[60,66,67,171]$ and disrupts sleep $[120,172]$; sleep disruption results in stress [173] with increased pain sensitivity [117, 174, 175]; pain produces stress $[58,61-64,66,68]$ and sleep disruption [117, 175-178]. Given the beneficial effects of exercise on stress and pain, reviewed above, it is not surprising that exercise has been reported to improve sleep latency, quality, efficiency, and duration and reduce next day tiredness [178$184]$.

\section{Methodological Considerations for Prevention of and Therapy for FMS Pain}

Ideally, a preventative/therapeutic regimen would not only have beneficial effects on stress, autonomic dysregulation, and pain but would directly or indirectly attenuate the multisystem aspects of FMS such as sleep disruption, depression, fatigue, and fibrofog. Exercise has the potential to accomplish these goals, but it is difficult to convince an FMS patient that an acutely painful activity will reduce pain in the long run. FMS pain can be increased during a bout of exercise $[77,185,186]$, and pain sensitivity can be increased at the conclusion of exercise $[77,187]$. Peripheral receptors that contribute to muscular pain and fatigue [38] are expressed and detected in leukocytes following exercise by individuals with FMS [75]. These effects are to be expected during and after working ischemic muscles. However, despite the barrier of activity-induced pain, carefully structured exercise programs can attenuate FMS pain and associated symptoms. Gradual introduction to an exercise protocol is especially important for FMS patients with chronic fatigue syndrome (CFS), for whom exertion can cause postexercise malaise for several days.

Numerous studies of exercise effects on FMS symptoms have been summarized in meta-analysis reviews that critically evaluate the experimental methods and summarize the results. The benefits of mild to moderate exercise programs for FMS uniformly include enhanced well being, improved physical fitness, and reduced disability [140, 141]. Because deconditioning commonly accompanies FMS [65], a strong case can be made for exercise as a standard component of FMS therapy. Furthermore, pain and/or tender point counts clearly are decreased by most exercise paradigms $[114,140,141,152-156]$. The success rate of exercise for pain is important, relative to therapies that rely exclusively on pharmacological agents with side effects and inherent difficulties associated with long-term usage [156]. However, individual differences in response to exercise result in a moderate overall (average) effect on FMS pain [141, 154, 156, 188]. Individual variability is considerable with respect to the severity, duration, and variety of FMS symptoms at the inception of treatment, and the duration of chronic pain is an important consideration. Also, the type and frequency of exercise and long-term compliance of the subjects influence the benefits of exercise therapy.

Typical experimental protocols for aerobic exercise have conducted supervised sessions 2 or 3 times per week [153$155]$, with varying recommendations for and documentation of exercise at home. Low to moderate levels of aerobic exercise, as defined by heart rate and blood pressure recordings, have been recommended [152-155]. Direct comparisons with strength training or stretching exercises have concluded that aerobic procedures provide better results $[141,154]$. The reasons for this conclusion are not clear, because assessments of presumed mechanistic bases for FMS are not included. For example, what are the relative effects of aerobic and strength exercises on indices of stress, autonomic regulation, and peripheral blood flow, and how are these effects related to reduction of deep muscular pain? In terms of peripheral mechanisms of FMS such as widespread muscular ischemia, it seems that an exercise protocol should enhance peripheral circulation globally, rather than for a specific set of muscles. This goal may be met by whole body aerobic exercise or strength training of multiple muscle groups, but documentation is needed. Also, summaries of exercise therapy for FMS have strongly recommended tailoring of parameters of exertion for each patient $[153,154,156,188]$. More specifically, (1) a level of exercise which is painful for a subject will discourage participation and may be deleterious [188]; (2) it is important to have exercise options that are adaptable to frequent use by individuals with different daily routines and/or physical limitations; (3) because chronic stress and autonomic dysregulation are relentless, exercise routines are likely to be most effective if conducted frequently so that peripheral blood flow is increased over a significant portion of each day.

The optimal schedule of exercise likely will depend upon the duration of increased blood flow that can be expected to accompany and follow each exercise period. Exercise training appears not to affect muscle blood flow at rest [189]. Thus, exercise therapy for FMS is at an important juncture, needing thorough investigations of long-term effects of different forms of exercise on blood supply to deep tissues. It is encouraging that studies involving standardized schedules of infrequent exercise have revealed attenuation of FMS symptoms, but there is little to be gained by continued study of set exercise paradigms with a fixed set of parameters that are chosen arbitrarily.

The optimum benefits of exercise for FMS surely will depend upon repeated, daily periods of exertion, but regularly scheduled laboratory sessions will be necessary to evaluate and adjust paradigms of exercise. Tolerance for exercise (exercise induced pain) can be assessed, both to maximize continued participation and to measure beneficial effects of exercise. If peripheral blood flow is increased over time with exercise, the threshold for exercise-induced pain should increase. Also, there should be a period free of clinical 
pain following each exercise period [186], and charting the time-course of this effect in relation to changes in blood flow to deep tissues would be instructive for design and modification of the exercise protocol. Resting levels of blood flow to muscles, as well as changes in blood flow in response to exercise or nociceptive stimulation, are regarded here as crucial information.

Previous studies have relied upon tender point counts as a measure of deep pain sensitivity, but a psychophysical test of pain during and after well-controlled compression of several muscle groups can provide more useful information on effects of exercise, over time, on sensitization of nociceptors in deep tissues. Psychophysical tests of sensitivity to cutaneous stimulation (e.g., temporal summation during repetitive stimulation) provide information on the central sensitization that is driven by tonic nociceptive input. Techniques for detection of biomarkers of gene expression have been shown to be particularly informative concerning levels of receptor expression and immune activation that are associated with muscular fatigue and pain $[75,190]$. These means for evaluation of mechanisms have provided opportunities to approach FMS as a medical condition. Until recently, there were questions as to whether FMS is psychosomatic, without an identifiable organic basis, in contrast to regional pain conditions with histories of injury to the painful tissues. Ironically, the mechanistic bases of FMS appear be identifiable and may also be correctable, in contrast to many regional pain conditions without available therapies that can silence the source of nociceptive input.

\section{Summary and Therapeutic Implications}

Fibromyalgia is a multiple-system disorder. FMS patients complain of chronic pain referred to deep tissues (and pain from exercise or palpation of muscles) and commonly present with depression, fibrofog, and sleep disruption. FMS patients frequently are in a deconditioned state with fatigue, and the widespread deep pain of FMS often coexists with one or more regional pain conditions. It is not feasible to treat each of these disorders separately (e.g., with pharmacological agents directed specifically to treat each disorder). This conundrum forces consideration of whether there is a fundamental mechanism for the symptoms that define FMS as a multiple-system disorder. Evidence summarized here identifies chronic psychological stress with autonomic dysregulation as the root cause of FMS, providing opportunities for mechanism-based prevention and therapy [191]. Pain referred to deep tissues is considered the primary symptom of FMS. Chronic stress reduces peripheral blood flow, resulting in widespread muscular ischemia, and muscular pain is a powerful stressor. Stress, with autonomic dysregulation and pain, also establishes central influences that enhance depression, impair mentation and sleep, and increase pain. Therefore, a therapy that reduces stress and/or pain could alleviate each of the multiple-system disorders of FMS. Remarkably, exercise exerts beneficial effects on stress and pain and the other FMS disorders. Reports documenting these effects are part of an extensive literature providing evidence for exercise as an effective therapy for many chronic diseases of a deconditioned modern society [192].

Investigations typically report moderate overall effects of exercise on FMS symptoms, attributable to the use of standardized exercise protocols despite considerable variability between patients. The use of fixed exercise protocols appears to suit scientific purposes but conflicts with a necessity to tailor exercise to each individual for the maximal therapeutic effect. Thus, it is recommended that different forms, frequencies, durations, and intensities of exercise be evaluated in terms of sustained normalization of peripheral blood flow for FMS individuals. Once an optimal pattern of exercise is established, it can be utilized with measurements of peripheral blood flow to guide individual variations in the exercise protocol over time. It can be expected that effective exercise protocols for pain reduction will differ between subjects and over time, as dictated by blood flow to muscles.

A mechanistic approach to FMS therapy and research minimizes the importance of a control group for comparison with treatments such as exercise. The therapeutic goal is to alleviate FMS, and important scientific goals are to evaluate relationships between FMS and suspected biological mechanisms for the FMS symptoms. At this point, these comparisons can be more instructive than group comparisons with and without exercise. For evaluation of FMS pain, it will be important to evaluate elicited ischemic pain in addition to standard verbal reports of ongoing pain. Wellcontrolled pressure stimulation of muscles with psychophysical evaluation of pain threshold and the suprathreshold intensity and duration of muscular pain is more informative than pressure point counts. Measurements of peripheral blood flow and exercise-induced expression of biomarkers for receptor expression and immune activation [75] are informative concerning peripheral effects of exercise. Assessments of distress, depression, sleep quality, and mentation provide a tracking of central effects of exercise.

Correction of deconditioning with exercise is beneficial for FMS patients, but available evidence indicates that psychological stress and peripheral vasoconstriction must be attenuated to alleviate pain referred to deep tissues. This paper has not covered techniques to relieve psychological stress directly, but they can be effective in combination with exercise, attenuating reciprocal interactions with pain and each of the multiple-system disorders of FMS.

\section{References}

[1] H. S. Smith, R. Harris, and D. Clauw, "Fibromyalgia: an afferent processing disorder leading to a complex pain generalized syndrome," Pain Physician, vol. 14, no. 2, pp. E217-E245, 2011.

[2] B. Gerdle, K. Söderberg, L. S. Puigvert, L. Rosendal, and B. Larsson, "Increased interstitial concentrations of pyruvate and lactate in the trapezius muscle of patients with fibromyalgia: a microdialysis study," Journal of Rehabilitation Medicine, vol. 42, no. 7, pp. 679-687, 2010.

[3] L. Bendtsen, J. NØrregaard, R. Jensen, and J. Olesen, "Evidence of qualitatively altered nociception in patientswith 
fibromyalgia," Arthritis and Rheumatism, vol. 40, no. 1, pp. 98-102, 1997.

[4] H. Y. Ge, H. Nie, P. Madeleine, B. Danneskiold-Samsøe, T. Graven-Nielsen, and L. Arendt-Nielsen, "Contribution of the local and referred pain from active myofascial trigger points in fibromyalgia syndrome," Pain, vol. 147, no. 1-3, pp. 233 240, 2009.

[5] H.-Y. Ge, Y. Wang, C. Fernández-de-las-Peñas, T. GravenNielsen, B. Danneskiold-Samsøe, and L. Arendt-Nielsen, "Reproduction of overall spontaneous pain pattern by manual stimulation of active myofascial trigger points in fibromyalgia patients," Arthritis Research and Therapy, vol. 13, no. 2, p. R48, 2011.

[6] E. Kosek, J. Ekholm, and P. Hansson, "Increased pressure pain sensibility in fibromyalgia patients is located deep to the skin but not restricted to muscle tissue," Pain, vol. 63, no. 3, pp. 335-339, 1995.

[7] M. Mikkelsson, P. Latikka, H. Kautiainen, R. Isomeri, and H. Isomaki, "Muscle and bone pressure pain threshold and pain tolerance in fibromyalgia patients and controls," Archives of Physical Medicine and Rehabilitation, vol. 73, no. 9, pp. 814818, 1992.

[8] R. Staud, R. C. Cannon, A. P. Mauderli, M. E. Robinson, D. D. Price, and C. J. Vierck, "Temporal summation of pain from mechanical stimulation of muscle tissue in normal controls and subjects with fibromyalgia syndrome," Pain, vol. 102, no. 1-2, pp. 87-95, 2003.

[9] K. C. Light, E. E. Bragdon, K. M. Grewen, K. A. Brownley, S. S. Girdler, and W. Maixner, "Adrenergic dysregulation and pain with and without acute beta-blockade in women with fibromyalgia and temporomandibular disorder," The Journal of Pain, vol. 10, no. 5, pp. 542-552, 2009.

[10] C. J. Vierck, "Mechanisms underlying development of spatially distributed chronic pain (fibromyalgia)," Pain, vol. 124, no. 3, pp. 242-263, 2006.

[11] G. K. Adler and R. Geenen, "Hypothalamic-pituitary-adrenal and autonomic nervous system functioning in fibromyalgia," Rheumatic Disease Clinics of North America, vol. 31, no. 1, pp. 187-202, 2005.

[12] K. I. Cho, J. H. Lee, H. G. Lee, S. M. Kim, and T. I. Kim, "Assessment of myocardial function in patients with fibromyalgia and the relationship to chronic emotional and physical stress," Korean Circulation Journal, vol. 40, no. 2, pp. 74-80, 2010.

[13] M. T. Dogru, G. Aydin, A. Tosun et al., "Correlations between autonomic dysfunction and circadian changes and arrhythmia prevalence in women with fibromyalgia syndrome," Anadolu Kardiyoloji Dergisi, vol. 9, no. 2, pp. 110-117, 2009.

[14] R. Furlan, S. Colombo, F. Perego et al., "Abnormalities of cardiovascular neural control and reduced orthostatic tolerance in patients with primary fibromyalgia," Journal of Rheumatology, vol. 32, no. 9, pp. 1787-1793, 2005.

[15] M. Martinez-Lavin, "Biology and therapy of fibromyalgia. Stress, the stress response system, and fibromyalgia," Arthritis Research and Therapy, vol. 9, no. 4, article 216, 2007.

[16] G. A. Reyes del Paso, S. Garrido, Á. Pulgar, and S. Duschek, "Autonomic cardiovascular control and responses to experimental pain stimulation in fibromyalgia syndrome," Journal of Psychosomatic Research, vol. 70, no. 2, pp. 125-134, 2011.

[17] K. A. Brownley, A. L. Hinderliter, S. G. West, S. S. Girdler, A. Sherwood, and K. C. Light, "Sympathoadrenergic mechanisms in reduced hemodynamic stress responses after exercise," Medicine and Science in Sports and Exercise, vol. 35, no. 6, pp. 978-986, 2003.

[18] J. C. Klein, C. G. Crandall, R. M. Brothers, and J. R. Carter, "Combined heat and mental stress alters neurovascular control in humans," Journal of Applied Physiology, vol. 109, no. 6, pp. 1880-1886, 2010.

[19] S. Roatta, M. Mohammed, and M. Passatore, "Detecting activation of the sympatho-adrenal axis from haemodynamic recordings, in conscious rabbits exposed to acute stress," Acta Physiologica, vol. 201, no. 3, pp. 323-337, 2011.

[20] L. Ghiadoni, A. E. Donald, M. Cropley et al., "Mental stress induces transient endothelial dysfunction in humans," Circulation, vol. 102, no. 20, pp. 2473-2478, 2000.

[21] L. E. Spieker, D. Hürlimann, F. Ruschitzka et al., "Mental stress induces prolonged endothelial dysfunction via endothelin-A receptors," Circulation, vol. 105, no. 24, pp. 2817-2820, 2002.

[22] Y. J. Chen, F. Huang, M. Zhang, and H. Y. Shang, "Psychological stress alters ultrastructure and energy metabolism of masticatory muscle in rats," Journal of Biomedicine and Biotechnology, vol. 2010, Article ID 302693, 9 pages, 2010.

[23] L. Bowyer, M. A. Brown, and M. Jones, "Vascular reactivity in men and women of reproductive age," American Journal of Obstetrics and Gynecology, vol. 185, no. 1, pp. 88-96, 2001.

[24] V. A. Converting, "Gender differences in autonomic functions associated with blood pressure regulation," American Journal of Physiology, vol. 275, no. 6, pp. R1909-R1920, 1998.

[25] J. P. Cooke, M. A. Craeger, P. J. Osmundson, and J. T. Shepherd, "Sex differences in control of cutaneous blood flow," Circulation, vol. 82, no. 5, pp. 1607-1615, 1990.

[26] J. M. Evans, M. G. Ziegler, A. R. Patwardhan et al., "Gender differences in autonomic cardiovascular regulation: spectral, hormonal, and hemodynamic indexes," Journal of Applied Physiology, vol. 91, no. 6, pp. 2611-2618, 2001.

[27] D. L. Kellogg, Y. Liu, and P. E. Pérgola, "Genome and hormones: gender differences in physiology selected contribution: gender differences in the endothelin-B receptor contribution to basal cutaneous vascular tone in humans," Journal of Applied Physiology, vol. 91, no. 5, pp. 2407-2411, 2001.

[28] H. Kim, C. Richardson, J. Roberts, L. Gren, and J. L. Lyon, "Cold hands, warm heart," The Lancet, vol. 351, no. 9114, p. 1492, 1998.

[29] I. Marchand, D. Johnson, D. Montgomery, G. R. Brisson, and H. Perrault, "Gender differences in temperature and vascular characteristics during exercise recovery," Canadian Journal of Applied Physiology, vol. 26, no. 5, pp. 425-441, 2001.

[30] J. P. Cooke, S. J. Creager, K. M. Scales et al., "Role of digital artery adrenoceptors in Raynaud's disease," Vascular Medicine, vol. 2, no. 1, pp. 1-7, 1997.

[31] J. P. Cooke and J. M. Marshall, "Mechanisms of Raynaud's disease," Vascular Medicine, vol. 10, no. 4, pp. 293-307, 2005.

[32] R. K. Oka, A. Szuba, J. C. Giacomini, and J. P. Cooke, "Gender differences in perception of PAD: a pilot study," Vascular Medicine, vol. 8, no. 2, pp. 89-94, 2003.

[33] A. H. Sadrzadeh Rafie, M. L. Stefanick, S. T. Sims et al., "Sex differences in the prevalence of peripheral artery disease in patients undergoing coronary catheterization," Vascular Medicine, vol. 15, no. 6, pp. 443-450, 2010.

[34] J. P. Fisher and P. J. Fadel, "Therapeutic strategies for targeting excessive central sympathetic activation in human 
hypertension," Experimental Physiology, vol. 95, no. 5, pp. 572-580, 2010.

[35] A. Rozanski, J. A. Blumenthal, and J. Kaplan, "Impact of psychological factors on the pathogenesis of cardiovascular disease and implications for therapy," Circulation, vol. 99, no. 16, pp. 2192-2217, 1999.

[36] J. Fagius, S. Karhuvaara, and G. Sundlof, “The cold pressor test: effects on sympathetic nerve activity in human muscle and skin nerve fascicles," Acta Physiologica Scandinavica, vol. 137, no. 3, pp. 325-334, 1989.

[37] Q. Zhou, R. B. Fillingim, J. L. Riley, and G. N. Verne, "Ischemic hypersensitivity in irritable bowel syndrome patients," Pain Medicine, vol. 11, no. 11, pp. 1619-1627, 2010.

[38] W. T. Birdsong, L. Fierro, F. G. Williams et al., "Sensing muscle ischemia: coincident detection of acid and ATP via interplay of two ion channels," Neuron, vol. 68, no. 4, pp. 739-749, 2010.

[39] X. Chen, P. G. Green, and J. D. Levine, "Stress enhances muscle nociceptor activity in the rat," Neuroscience, vol. 185, pp. 166-173, 2011.

[40] W. Magerl, G. Geldner, and H. O. Handwerker, "Pain and vascular reflexes in man elicited by prolonged noxious mechano-stimulation," Pain, vol. 43, no. 2, pp. 219-225, 1990.

[41] M. Nordin and J. Fagius, "Effect of noxious stimulation on sympathetic vasoconstrictor outflow to human muscles," Journal of Physiology, vol. 489, no. 3, pp. 885-894, 1995.

[42] R. Staud, M. E. Robinson, and D. D. Price, "Temporal summation of second pain and its maintenance are useful for characterizing widespread central sensitization of fibromyalgia patients," The Journal of Pain, vol. 8, no. 11, pp. 893-901, 2007.

[43] R. Staud, C. J. Vierck, R. L. Cannon, A. P. Mauderli, and D. D. Price, "Abnormal sensitization and temporal summation of second pain (wind-up) in patients with fibromyalgia syndrome," Pain, vol. 91, no. 1-2, pp. 165-175, 2001.

[44] D. D. Price, Q. Zhou, B. Moshiree, M. E. Robinson, and G. N. Verne, "Peripheral and central contributions to hyperalgesia in irritable bowel syndrome," The Journal of Pain, vol. 7, no. 8, pp. 529-535, 2006.

[45] E. E. Ayesh, T. S. Jensen, and P. Svensson, "Hypersensitivity to mechanical and intra-articular electrical stimuli in persons with painful temporomandibular joints," Journal of Dental Research, vol. 86, no. 12, pp. 1187-1192, 2007.

[46] M. Bouin, P. Meunier, M. Riberdy-Poitras, and P. Poitras, "Pain hypersensitivity in patients with functional gastrointestinal disorders: a gastrointestinal-specific defect or a general systemic condition?" Digestive Diseases and Sciences, vol. 46, article 216, p. 7, 2007.

[47] C. Fernández-de-las-Peñas, F. Galán-del-Río, J. FernándezCarnero, J. Pesquera, L. Arendt-Nielsen, and P. Svensson, "Bilateral widespread mechanical pain sensitivity in women with myofascial temporomandibular disorder: evidence of impairment in central nociceptive processing," The Journal of Pain, vol. 10, no. 11, pp. 1170-1178, 2009.

[48] C. Fernández-de-las-Peñas, R. Ortega-Santiago, M. L. Cuadrado, C. López-de-Silanes, and J. A. Pareja, "Bilateral widespread mechanical pain hypersensitivity as sign of central sensitization in patients with cluster headache," Headache, vol. 51, no. 3, pp. 384-391, 2011.

[49] C. Fernández-Lao, I. Cantarero-Villanueva, C. Fernándezde-Las-Peñas, R. del-Moral-Ávila, S. Menjón-Beltrán, and M. Arroyo-Morales, "Widespread mechanical pain hypersensitivity as a sign of central sensitization after breast cancer surgery: comparison between mastectomy and lumpectomy," Pain Medicine, vol. 12, no. 1, pp. 72-78, 2011.

[50] L. L. Kindler, K. D. Jones, N. Perrin, and R. M. Bennett, "Risk factors predicting the development of widespread pain from chronic back or neck pain," The Journal of Pain, vol. 11, no. 12, pp. 1320-1328, 2010.

[51] R. B. Leistad, T. Sand, R. H. Westgaard, K. B. Nilsen, and L. J. Stovner, "Stress-induced pain and muscle activity in patients with migraine and tension-type headache," Cephalalgia, vol. 26, no. 1, pp. 64-73, 2006.

[52] W. Maixner, R. Fillingim, A. Sigurdsson, Shelley Kincaid, and S. Silva, "Sensitivity of patients with painful temporomandibular disorders to experimentally evoked pain: evidence for altered temporal summation of pain," Pain, vol. 76, no. 1-2, pp. 71-81, 1998.

[53] M. Piché, M. Arsenault, P. Poitras, P. Rainville, and M. Bouin, "Widespread hypersensitivity is related to altered pain inhibition processes in irritable bowel syndrome," Pain, vol. 148 , no. 1, pp. 49-58, 2010.

[54] A. C. Rodrigues, G. N. Verne, S. Schmidt, and A. P. Mauderli, "Hypersensitivity to cutaneous thermal nociceptive stimuli in irritable bowel syndrome," Pain, vol. 115, no. 1-2, pp. 511, 2005.

[55] E. Sarlani and J. D. Greenspan, "Evidence for generalized hyperalgesia in temporomandibular disorders patients," Pain, vol. 102, no. 3, pp. 221-226, 2003.

[56] P. Svensson, T. List, and G. Hector, "Analysis of stimulusevoked pain in patients with myofascial temporomandibular pain disorders," Pain, vol. 92, no. 3, pp. 399-409, 2001.

[57] C. H. Wilder-Smith and J. Robert-Yap, "Abnormal endogenous pain modulation and somatic and visceral hypersensitivity in female patients with irritable bowel syndrome," World Journal of Gastroenterology, vol. 13, no. 27, pp. 36993704, 2007.

[58] Q. Zhou, R. B. Fillingim, J. L. Riley, W. B. Malarkey, and G. N. Verne, "Central and peripheral hypersensitivity in the irritable bowel syndrome," Pain, vol. 148, no. 3, pp. 454-461, 2010.

[59] Q. Q. Zhou, R. B. Fillingim, J. L. Riley, and G. N. Verne, "Thermal hypersensitivity in a subset of irritable bowel syndrome patients," World Journal of Gastroenterology, vol. 15, no. 26, pp. 3254-3260, 2009.

[60] J. N. Ablin, H. Cohen, D. J. Clauw et al., "A tale of two citiesthe effect of low intensity conflict on prevalence and characteristics of musculoskeletal pain and somatic symptoms associated with chronic stress," Clinical and Experimental Rheumatology, vol. 28, no. 6, supplement 63, pp. S15-S21, 2010.

[61] S. Bruehl, J. W. Burns, and J. A. McCubbin, "Altered cardiovascular/pain regulatory relationships in chronic pain," International Journal of Behavioral Medicine, vol. 5, no. 1, pp. 63-75, 1998.

[62] C. R. Chapman, R. P. Tuckett, and C. W. Song, "Pain and stress in a systems perspective: reciprocal neural, endocrine, and immune interactions," The Journal of Pain, vol. 9, no. 2, pp. 122-145, 2008.

[63] D. M. Hallman, L. G. Lindberg, B. B. Arnetz, and E. Lyskov, "Effects of static contraction and cold stimulation on cardiovascular autonomic indices, trapezius blood flow and muscle activity in chronic neck-shoulder pain," European Journal of Applied Physiology, pp. 1-11, 2011.

[64] A. C. Johansson, L. G. Gunnarsson, S. J. Linton et al., "Pain, disability and coping reflected in the diurnal cortisol 
variability in patients scheduled for lumbar disc surgery," European Journal of Pain, vol. 12, no. 5, pp. 633-640, 2008.

[65] J. Jones, D. N. Rutledge, K. D. Jones, L. Matallana, and D. S. Rooks, "Self-assessed physical function levels of women with fibromyalgia: a national survey," Women's Health Issues, vol. 18, no. 5, pp. 406-412, 2008.

[66] J. McBeth, A. J. Silman, A. Gupta et al., "Moderation of psychosocial risk factors through dysfunction of the hypothalamic-pituitary-adrenal stress axis in the onset of chronic widespread musculoskeletal pain: findings of a population-based prospective cohort study," Arthritis and Rheumatism, vol. 56, no. 1, pp. 360-371, 2007.

[67] K. G. Raphael and C. S. Widom, "Post-traumatic stress disorder moderates the relation between documented childhood victimization and pain 30 years later," Pain, vol. 152, no. 1, pp. 163-169, 2011.

[68] E. J. Videlock, M. Adeyemo, A. Licudine et al., "Childhood trauma is associated with hypothalamic-pituitary-adrenal axis responsiveness in irritable bowel syndrome," Gastroenterology, vol. 137, no. 6, pp. 1954-1962, 2009.

[69] W. Grassi, P. Core, G. Carlino, F. Salaffi, and C. Cervini, "Capillary permeability in fibromyalgia," Journal of Rheumatology, vol. 21, no. 7, pp. 1328-1331, 1994.

[70] M. Jeschonneck, G. Grohmann, G. Hein, and H. Sprott, "Abnormal microcirculation and temperature in skin above tender points in patients with fibromyalgia," Rheumatology, vol. 39, no. 8, pp. 917-921, 2000.

[71] D. L. Katz, L. Greene, A. Ali, and Z. Faridi, "The pain of fibromyalgia syndrome is due to muscle hypoperfusion induced by regional vasomotor dysregulation," Medical Hypotheses, vol. 69, no. 3, pp. 517-525, 2007.

[72] N. Lund, A. Bengtsson, and P. Thorborg, "Muscle tissue oxygen pressure in primary fibromyalgia," Scandinavian Journal of Rheumatology, vol. 15, no. 2, pp. 165-173, 1986.

[73] S. Morf, B. Amann-Vesti, A. Forster et al., "Microcirculation abnormalities in patients with fibromyalgia-measured by capillary microscopy and laser fluxmetry," Arthritis Research \& Therapy, vol. 7, no. 2, pp. R209-R216, 2005.

[74] A. Elvin, A. K. Siösteen, A. Nilsson, and E. Kosek, "Decreased muscle blood flow in fibromyalgia patients during standardised muscle exercise: a contrast media enhanced colour doppler study," European Journal of Pain, vol. 10, no. 2, pp. 137-144, 2006.

[75] A. R. Light, A. T. White, R. W. Hughen, and K. C. Light, "Moderate exercise increases expression for sensory, adrenergic, and immune genes in chronic fatigue syndrome patients but not in normal subjects," The Journal of Pain, vol. 10, no. 10, pp. 1099-1112, 2009.

[76] J. Elert, S. Aspegren Kendall, B. Larsson, B. Månsson, and B. Gerdle, "Chronic pain and difficulty in relaxing postural muscles in patients with fibromyalgia and chronic whiplash associated disorders," Journal of Rheumatology, vol. 28, no. 6, pp. 1361-1368, 2001.

[77] D. Kadetoff and E. Kosek, "Evidence of reduced sympathoadrenal and hypothalamic-pituitary activity during static muscular work in patients with fibromyalgia," Journal of Rehabilitation Medicine, vol. 42, no. 8, pp. 765-772, 2010.

[78] C. A. Griffis, P. Compton, and L. Doering, "The effect of pain on leukocyte cellular adhesion molecules," Biological Research for Nursing, vol. 7, no. 4, pp. 297-312, 2006.

[79] P. E. Molina, "Neurobiology of the stress response: contribution of the sympathetic nervous system to the neuroimmune axis in traumatic injury," Shock, vol. 24, no. 1, pp. 3-10, 2005.
[80] E. Ortega, J. J. García, M. E. Bote et al., "Exercise in fibromyalgia and related inflammatory disorders: known effects and unknown chances," Exercise Immunology Review, vol. 15, pp. 42-65, 2009.

[81] R. L. Ross, K. D. Jones, R. M. Bennett, R. L. Ward, B. J. Druker, and L. J. Wood, "Preliminary evidence of increased pain and elevated cytokines in fibromyalgia patients with defective growth hormone response to exercise," The Open Immunology Journal, vol. 3, pp. 9-18, 2010.

[82] D. J. Wallace, M. Linker-Israeli, D. Hallegua, S. Silverman, D. Silver, and M. H. Weisman, "Cytokines play an aetiopathogenetic role in fibromyalgia: a hypothesis and pilot study," Rheumatology, vol. 40, no. 7, pp. 743-749, 2001.

[83] M. D. Cordero, M. de Miguel, A. M. Moreno Fernandez et al., "Mitochondrial dysfunction and mitophagy activation in blood mononuclear cells of fibromyalgia patients: implication in the pathogenesis of the disease," Arthritis Research \& Therapy, p. R17, 2010.

[84] E. J. C. de Geus, L. J. P. van Doornen, D. C. de Visser, and J. F. Orlebeke, "Existing and training induced differences in aerobic fitness: their relationship to physiological response patterns during different types of stress," Psychophysiology, vol. 27, no. 4, pp. 457-478, 1990.

[85] J. Duda, D. Sedlock, C. Melby, and C. Thaman, "The effects of physical activity level and acute exercise on heart rate and subjective response to a psychological stressor," International Journal of Sport Psychology, vol. 19, pp. 119-133, 1988.

[86] F. Peronnet, D. Massicotte, J. E. Paquet, G. Brisson, and J. de Champlain, "Blood pressure and plasma catecholamine responses to various challenges during exercise-recovery in man," European Journal of Applied Physiology and Occupational Physiology, vol. 58, no. 5, pp. 551-555, 1989.

[87] W. Rejeski, E. Gregg, A. Thompson, and M. Berry, "The effects of varying doses of acute aerobic exercise on psychophysiological stress responses in highly trained cyclists," Journal of Sport \& Exercise Psychology, vol. 13, pp. 188-199, 1991.

[88] M. Roy and A. Steptoe, "The inhibition of cardiovascular responses to mental stress following aerobic exercise," Psychophysiology, vol. 28, no. 6, pp. 689-700, 1991.

[89] M. C. Laterza, L. D. N. J. de Matos, I. C. Trombetta et al., "Exercise training restores baroreflex sensitivity in nevertreated hypertensive patients," Hypertension, vol. 49, no. 6, pp. 1298-1306, 2007.

[90] L. Nelson, G. L. Jennings, M. D. Esler, and P. I. Korner, "Effect of changing levels of physical activity on blood-pressure and haemodynamics in essential hypertension," The Lancet, vol. 2, no. 8505, pp. 473-476, 1986.

[91] F. P. Leung, L. M. Yung, I. Laher, X. Yao, Z. Y. Chen, and Y. Huang, "Exercise, vascular wall and cardiovascular diseases: an update (part 1)," Sports Medicine, vol. 38, no. 12, pp. 10091024, 2008.

[92] B. Høier, K. Olsen, M. Nyberg, J. Bangsbo, and Y. Hellsten, "Contraction-induced secretion of VEGF from skeletal muscle cells is mediated by adenosine," American Journal of Physiology, vol. 299, no. 3, pp. H857-H862, 2010.

[93] J. Chinsomboon, J. Ruas, R. K. Gupta et al., "The transcriptional coactivator PGC- $1 \alpha$ mediates exercise-induced angiogenesis in skeletal muscle," Proceedings of the National Academy of Sciences of the United States of America, vol. 106, no. 50, pp. 21401-21406, 2009.

[94] F. A. M. Huber-Abel, M. Gerber, H. Hoppeler, and O. Baum, "Exercise-induced angiogenesis correlates with the 
up-regulated expression of neuronal nitric oxide synthase (nNOS) in human skeletal muscle," European Journal of Applied Physiology. In press.

[95] C. L. Dumke, J. M. Davis, E. A. Murphy et al., "Successive bouts of cycling stimulates genes associated with mitochondrial biogenesis," European Journal of Applied Physiology, vol. 107, no. 4, pp. 419-427, 2009.

[96] E. Børsheim and R. Bahr, "Effect of exercise intensity, duration and mode on post-exercise oxygen consumption," Sports Medicine, vol. 33, no. 14, pp. 1037-1060, 2003.

[97] B. R. Jensen, G. Sjogaard, S. Bornmyr, M. Arborelius, and K. Jorgensen, "Intramuscular laser-Doppler flowmetry in the supraspinatus muscle during isometric contractions," European Journal of Applied Physiology and Occupational Physiology, vol. 71, no. 4, pp. 373-378, 1995.

[98] S. E. Larsson, H. Cai, Q. Zhang, R. Larsson, and P. A. Oberg, "Measurement by laser-Doppler flowmetry of microcirculation in lower leg muscle at different blood fluxes in relation to electromyographically determined contraction and accumulated fatigue," European Journal of Applied Physiology and Occupational Physiology, vol. 70, no. 4, pp. 288-293, 1995.

[99] B. Saltin, "Exercise hyperaemia: magnitude and aspects on regulation in humans," Journal of Physiology, vol. 583, no. 3, pp. 819-823, 2007.

[100] V. Strøm, S. Knardahl, J. K. Stanghelle, and C. Røe, "Pain induced by a single simulated office-work session: time course and association with muscle blood flux and muscle activity," European Journal of Pain, vol. 13, no. 8, pp. 843-852, 2009.

[101] J. A. L. Calbert, M. Jensen-Urstad, G. van Hall, H. C. Holmberg, H. Rosdahl, and B. Saltin, "Maximal muscular vascular conductances during whole body upright exercise in humans," Journal of Physiology, vol. 558, no. 1, pp. 319-331, 2004.

[102] J. A. L. Calbet, J. Gonzalez-Alonso, J. W. Helge et al., "Cardiac output and leg and arm blood flow during incremental exercise to exhaustion on the cycle ergometer," Journal of Applied Physiology, vol. 103, no. 3, pp. 969-978, 2007.

[103] P. Thaning, L. T. Bune, M. Zaar, B. Saltin, and J. B. Rosenmeier, "Functional sympatholysis during exercise in patients with type 2 diabetes with intact response to acetylcholine," Diabetes Care, vol. 34, no. 5, pp. 1186-1191, 2011.

[104] J. S. Floras, C. A. Sinkey, P. E. Aylward, D. R. Seals, P. N. Thoren, and A. L. Mark, "Postexercise hypotension and sympathoinhibition in borderline hypertensive men," Hypertension, vol. 14, no. 1, pp. 28-35, 1989.

[105] H. S. Dod, R. Bhardwaj, V. Sajja et al., "Effect of intensive lifestyle changes on endothelial function and on inflammatory markers of atherosclerosis," American Journal of Cardiology, vol. 105, no. 3, pp. 362-367, 2010.

[106] G. L. Ghisi, A. Durieux, R. Pinho, and M. Benetti, "Physical exercise and endothelial dysfunction," Arquivos Brasileiros de Cardiologia, vol. 95, no. 5, pp. e130-e137, 2010.

[107] S. Erbs, R. Höllriegel, A. Linke et al., "Exercise training in patients with advanced chronic heart failure (NYHA IIIb) promotes restoration of peripheral vasomotor function, induction of endogenous regeneration, and improvement of left ventricular function," Circulation: Heart Failure, vol. 3, no. 4, pp. 486-494, 2010.

[108] C. T. Minson, "Thermal provocation to evaluate microvascular reactivity in human skin," Journal of Applied Physiology, vol. 109, no. 4, pp. 1239-1246, 2010.
[109] S. Biro, A. Masuda, T. Kihara, and C. Tei, "Clinical implications of thermal therapy in lifestyle-related diseases," Experimental Biology and Medicine, vol. 228, no. 10, pp. 1245-1249, 2003.

[110] T. Kihara, S. Biro, M. Imamura et al., "Repeated sauna treatment improves vascular endothelial and cardiac function in patients with chronic heart failure," Journal of the American College of Cardiology, vol. 39, no. 5, pp. 754-759, 2002.

[111] M. Miyata and C. Tei, "Waon therapy for cardiovascular disease: innovative therapy for the 21st century," Circulation Journal, vol. 74, no. 4, pp. 617-621, 2010.

[112] T. Brockow, A. Wagner, A. Franke, M. Offenbächer, and K. L. Resch, "A randomized controlled trial on the effectiveness of mild water-filtered near infrared whole-body hyperthermia as an adjunct to a standard multimodal rehabilitation in the treatment of fibromyalgia," The Clinical journal of pain, vol. 23, no. 1, pp. 67-75, 2007.

[113] K. Matsushita, A. Masuda, and C. Tei, "Efficacy of Waon therapy for fibromyalgia," Internal Medicine, vol. 47, no. 16, pp. 1473-1476, 2008.

[114] S. E. Gowans and A. DeHueck, "Pool exercise for individuals with fibromyalgia," Current Opinion in Rheumatology, vol. 19, no. 2, pp. 168-173, 2007.

[115] K. Mannerkorpi, M. Ahlmén, and C. Ekdahl, "Six- and 24month follow-up of pool exercise therapy and education for patients with fibromyalgia," Scandinavian Journal of Rheumatology, vol. 31, no. 5, pp. 306-310, 2002.

[116] F. Wolfe, D. J. Clauw, M. A. Fitzcharles et al., "The American College of Rheumatology preliminary diagnostic criteria for fibromyalgia and measurement of symptom severity," Arthritis Care and Research, vol. 62, no. 5, pp. 600-610, 2010.

[117] T. M. Palermo, A. C. Wilson, A. S. Lewandowski, M. ToliverSokol, and C. B. Murray, "Behavioral and psychosocial factors associated with insomnia in adolescents with chronic pain," Pain, vol. 152, no. 1, pp. 89-94, 2011.

[118] D. G. Baker, C. M. Nievergelt, and D. T. O'Connor, "Biomarkers of PTSD: neuropeptides and immune signaling," Neuropharmacology. In press.

[119] G. Belleville, S. Guay, and A. Marchand, "Persistence of sleep disturbances following cognitive-behavior therapy for posttraumatic stress disorder," Journal of Psychosomatic Research, vol. 70, no. 4, pp. 318-327, 2011.

[120] T. Fenzl, C. Touma, C. P.N. Romanowski et al., "Sleep disturbances in highly stress reactive mice: modeling endophenotypes of major depression," BMC Neuroscience, vol. 12, article 29, 2011.

[121] T. A. Brown and A. J. Rosellini, "The direct and interactive effects of neuroticism and life stress on the severity and longitudinal course of depressive symptoms," Journal of Abnormal Psychology. In press.

[122] J. A. Sumner, J. W. Griffith, S. Mineka, K. N. Rekart, R. E. Zinbarg, and M. G. Craske, "Overgeneral autobiographical memory and chronic interpersonal stress as predictors of the course of depression in adolescents," Cognition and Emotion, vol. 25, no. 1, pp. 183-192, 2011.

[123] M.-F. Marin, C. Lord, J. Andrews et al., "Chronic stress, cognitive functioning and mental health," Neurobiology of Learning and Memory. In press.

[124] C. Sandi and M. T. Pinelo-Nava, "Stress and memory: behavioral effects and neurobiological mechanisms," Neural Plasticity, vol. 2007, Article ID 78970, 20 pages, 2007.

[125] P. Andreski, H. Chilcoat, and N. Breslau, "Post-traumatic stress disorder and somatization symptoms: a prospective study," Psychiatry Research, vol. 79, no. 2, pp. 131-138, 1998. 
[126] G. J. G. Asmundson, M. J. Coons, S. Taylor, and J. Katz, "PTSD and the experience of pain: research and clinical implications of shared vulnerability and mutual maintenance models," Canadian Journal of Psychiatry, vol. 47, no. 10, pp. 930-937, 2002.

[127] J. C. Beckham, A. L. Crawford, M. E. Feldman et al., "Chronic posttraumatic stress disorder and chronic pain in Vietnam combat veterans," Journal of Psychosomatic Research, vol. 43, no. 4, pp. 379-389, 1997.

[128] E. Fries, J. Hesse, J. Hellhammer, and D. H. Hellhammer, "A new view on hypocortisolism," Psychoneuroendocrinology, vol. 30, no. 10, pp. 1010-1016, 2005.

[129] A. C. Mcfarlane, M. Atchison, E. Rafalowicz, and P. Papay, "Physical symptoms in post-traumatic stress disorder," Journal of Psychosomatic Research, vol. 38, no. 7, pp. 715-726, 1994.

[130] M. Muse, "Stress-related, posttraumatic chronic pain syndrome: criteria for diagnosis, and preliminary report on prevalence," Pain, vol. 23, no. 3, pp. 295-300, 1985.

[131] T. J. Sharp and A. G. Harvey, "Chronic pain and posttraumatic stress disorder: mutual maintenance?" Clinical Psychology Review, vol. 21, no. 6, pp. 857-877, 2001.

[132] G. D. Slade, L. Diatchenko, K. Bhalang et al., "Influence of psychological factors on risk of temporomandibular disorders," Journal of Dental Research, vol. 86, no. 11, pp. 1120-1125, 2007.

[133] M. Hummel, T. Cummons, P. Lu et al., "Pain is a salient "stressor" that is mediated by corticotropin-releasing factor1 receptors," Neuropharmacology, vol. 59, no. 3, pp. 160-166, 2010.

[134] S. B. Norman, M. B. Stein, J. E. Dimsdale, and D. B. Hoyt, "Pain in the aftermath of trauma is a risk factor for posttraumatic stress disorder," Psychological Medicine, vol. 38, no. 4, pp. 533-542, 2008.

[135] A. Peckerman, B. E. Hurwitz, P. G. Saab, M. M. Llabre, P. M. McCabe, and N. Schneiderman, "Stimulus dimensions of the cold pressor test and the associated patterns of cardiovascular response," Psychophysiology, vol. 31, no. 3, pp. 282-290, 1994.

[136] M. Rigaud, G. Gemes, S. E. Abram et al., "Pain tests provoke modality-specific cardiovascular responses in awake, unrestrained rats," Pain, vol. 152, no. 2, pp. 274-284, 2011.

[137] C. J. Vierck, M. Green, and R. P. Yezierski, "Pain as a stressor: effects of prior nociceptive stimulation on escape responding of rats to thermal stimulation," European Journal of Pain, vol. 14, no. 1, pp. 11-16, 2010.

[138] J. Moses, A. Steptoe, A. Mathews, and S. Edwards, "The effects of exercise training on mental well-being in the normal population: a controlled trial," Journal of Psychosomatic Research, vol. 33, no. 1, pp. 47-61, 1989.

[139] C. J. Lavie, R. V. Milani, J. H. O’Keefe, and T. J. Lavie, "Impact of exercise training on psychological risk factors," Progress in Cardiovascular Diseases, vol. 53, no. 6, pp. 464-470, 2011.

[140] L. Brosseau, G. A. Wells, P. Tugwell et al., "Ottawa panel evidence-based clinical practice guidelines for aerobic fitness exercises in the management of fibromyalgia: part 1," Physical Therapy, vol. 88, no. 7, pp. 857-871, 2008.

[141] A. J. Busch, C. L. Schachter, T. J. Overend, P. M. Peloso, and K. A. R. Barber, "Exercise for fibromyalgia: a systematic review," Journal of Rheumatology, vol. 35, no. 6, pp. 1130-1144, 2008.

[142] I. A. Strigo, A. N. Simmons, S. C. Matthews, A. D. Craig, and M. P. Paulus, "Increased affective bias revealed using experimental graded heat stimuli in young depressed adults: evidence of "emotional allodynia"', Psychosomatic Medicine, vol. 70, no. 3, pp. 338-344, 2008.

[143] G. E. Plante, "Depression and cardiovascular disease: a reciprocal relationship," Metabolism, vol. 54, no. 5, pp. 4548,2005

[144] B. L. Jacobs, H. van Praag, and F. H. Gage, "Adult brain neurogenesis and psychiatry: a novel theory of depression," Molecular Psychiatry, vol. 5, no. 3, pp. 262-269, 2000.

[145] B. S. McEwen, "The neurobiology of stress: from serendipity to clinical relevance," Brain Research, vol. 886, no. 1-2, pp. 172-189, 2000.

[146] P. R. Croft, A. C. Papageorgiou, S. Ferry, E. Thomas, M. I. V. Jayson, and A. J. Silman, "Psychologic distress and low back pain: evidence from a prospective study in the general population," Spine, vol. 20, no. 24, pp. 2731-2737, 1995.

[147] P. Leino and G. Magni, "Depressive and distress symptoms as predictors of low back pain, neck-shoulder pain, and other musculoskeletal morbidity: a 10-year follow-up of metal industry employees," Pain, vol. 53, no. 1, pp. 89-94, 1993.

[148] W. Katon, K. Egan, and D. Miller, "Chronic pain: lifetime psychiatric diagnoses and family history," American Journal of Psychiatry, vol. 142, no. 10, pp. 1156-1160, 1985.

[149] S. J. Linton, "A review of psychological risk factors in back and neck pain," Spine, vol. 25, no. 9, pp. 1148-1156, 2000.

[150] M. D. Gayman, R. L. Brown, and M. Cui, "Depressive symptoms and bodily pain: the role of physical disability and social stress," Stress and Health, vol. 27, no. 1, pp. 52-63, 2011.

[151] M. J. Bair, R. L. Robinson, W. Katon, and K. Kroenke, "Depression and pain comorbidity: a literature review," Archives of Internal Medicine, vol. 163, no. 20, pp. 2433-2445, 2003.

[152] M. Cazzola, F. Atzeni, F. Salaffi, S. Stisi, G. Cassisi, and P. Sarzi-Puttini, "What kind of exercise is best in fibromyalgia therapeutic programmes? A practical review," Clinical and Experimental Rheumatology, vol. 28, no. 6, supplement 63, pp. S117-S124, 2010.

[153] W. Hauser, P. Klose, J. Langhorst et al., "Efficacy of different types of aerobic exercise in fibromyalgia syndrome: a systematic review and meta-analysis of randomised controlled trials," Arthritis Research \& Therapy, vol. 12, p. R79, 2010.

[154] K. Mannerkorpi and M. D. Iversen, "Physical exercise in fibromyalgia and related syndromes," Best Practice and Research: Clinical Rheumatology, vol. 17, no. 4, pp. 629-647, 2003.

[155] E. N. Thomas and F. Blotman, "Aerobic exercise in fibromyalgia: a practical review," Rheumatology International, vol. 30, no. 9, pp. 1143-1150, 2010.

[156] S. van Koulil, M. Effting, F. W. Kraaimaat et al., "Cognitivebehavioural therapies and exercise programmes for patients with fibromyalgia: state of the art and future directions," Annals of the Rheumatic Diseases, vol. 66, no. 5, pp. 571-581, 2007.

[157] J. A. Blumenthal, M. A. Babyak, K. A. Moore et al., "Effects of exercise training on older patients with major depression," Archives of Internal Medicine, vol. 159, no. 19, pp. 2349-2356, 1999.

[158] R. Canbeyli, "Sensorimotor modulation of mood and depression: an integrative review," Behavioural Brain Research, vol. 207, no. 2, pp. 249-264, 2010.

[159] C. Nabkasorn, N. Miyai, A. Sootmongkol et al., "Effects of physical exercise on depression, neuroendocrine stress hormones and physiological fitness in adolescent females with depressive symptoms," European Journal of Public Health, vol. 16, no. 2, pp. 179-184, 2006. 
[160] D. I. Galper, M. H. Trivedi, C. E. Barlow, A. L. Dunn, and J. B. Kampert, "Inverse association between physical inactivity and mental health in men and women," Medicine and Science in Sports and Exercise, vol. 38, no. 1, pp. 173-178, 2006.

[161] W. J. Kop, A. A. Weinstein, P. A. Deuster, K. S. Whittaker, and R. P. Tracy, "Inflammatory markers and negative mood symptoms following exercise withdrawal," Brain, Behavior, and Immunity, vol. 22, no. 8, pp. 1190-1196, 2008.

[162] M. Joëls, Z. Pu, O. Wiegert, M. S. Oitzl, and H. J. Krugers, "Learning under stress: how does it work?" Trends in Cognitive Sciences, vol. 10, no. 4, pp. 152-158, 2006.

[163] J. J. Cerqueira, F. Mailliet, O. F. X. Almeida, T. M. Jay, and N. Sousa, "The prefrontal cortex as a key target of the maladaptive response to stress," Journal of Neuroscience, vol. 27, no. 11, pp. 2781-2787, 2007.

[164] J. J. Radley, A. B. Rocher, M. Miller et al., "Repeated stress induces dendritic spine loss in the rat medial prefrontal cortex," Cerebral Cortex, vol. 16, no. 3, pp. 313-320, 2006.

[165] V. Duric and K. E. McCarson, "Persistent pain produces stress-like alterations in hippocampal neurogenesis and gene expression," The Journal of Pain, vol. 7, no. 8, pp. 544-555, 2006.

[166] R. M. Thomas, G. Hotsenpiller, and D. A. Peterson, "Acute psychosocial stress reduces cell survival in adult hippocampal neurogenesis without altering proliferation," Journal of Neuroscience, vol. 27, no. 11, pp. 2734-2743, 2007.

[167] R. S. Duman, J. Malberg, S. Nakagawa, and C. D’Sa, “Neuronal plasticity and survival in mood disorders," Biological Psychiatry, vol. 48, no. 8, pp. 732-739, 2000.

[168] C. W. Cotman, N. C. Berchtold, and L. A. Christie, "Exercise builds brain health: key roles of growth factor cascades and inflammation," Trends in Neurosciences, vol. 30, no. 9, pp. 464-472, 2007.

[169] A. F. Kramer, K. I. Erickson, and S. J. Colcombe, "Exercise, cognition, and the aging brain," Journal of Applied Physiology, vol. 101, no. 4, pp. 1237-1242, 2006.

[170] E. B. Larson, L. Wang, J. D. Bowen et al., "Exercise is associated with reduced risk for incident dementia among persons 65 years of age and older," Annals of Internal Medicine, vol. 144, no. 2, pp. 73-81, 2006.

[171] E. A. Jones, J. McBeth, B. Nicholl et al., "What characterizes persons who do not report musculoskeletal pain? Results from a 4-year population-based longitudinal study (The Epifund Study)," Journal of Rheumatology, vol. 36, no. 5, pp. 1071-1077, 2009.

[172] S. van Liempt, E. Vermetten, E. Geuze, and H. G. M. Westenberg, "Pharmacotherapy for disordered sleep in posttraumatic stress disorder: a systematic review," International Clinical Psychopharmacology, vol. 21, no. 4, pp. 193-202, 2006.

[173] P. Meerlo, A. Sgoifo, and D. Suchecki, "Restricted and disrupted sleep: effects on autonomic function, neuroendocrine stress systems and stress responsivity," Sleep Medicine Reviews, vol. 12, no. 3, pp. 197-210, 2008.

[174] M. Haack, E. Lee, D. A. Cohen, and J. M. Mullington, "Activation of the prostaglandin system in response to sleep loss in healthy humans: potential mediator of increased spontaneous pain," Pain, vol. 145, no. 1-2, pp. 136-141, 2009.

[175] S. Lautenbacher, B. Kundermann, and J. C. Krieg, "Sleep deprivation and pain perception," Sleep Medicine Reviews, vol. 10, no. 5, pp. 357-369, 2006.

[176] E. P. Calandre, M. L. Rodriguez-Claro, F. Rico-Villademoros, J. S. Vilchez, J. Hidalgo, and A. Delgado-Rodriguez, "Effects of pool-based exercise in fibromyalgia symptomatology and sleep quality: a prospective randomised comparison between stretching and Ai Chi," Clinical and Experimental Rheumatology, vol. 27, no. 5, pp. S21-S28, 2009.

[177] L. K. Sprod, O. G. Palesh, M. C. Janelsins et al., "Exercise, sleep quality, and mediators of sleep in breast and prostate cancer patients receiving radiation therapy," Community Oncology, vol. 7, no. 10, pp. 463-471, 2010.

[178] M. F. Tang, T. H. Liou, and C. C. Lin, "Improving sleep quality for cancer patients: benefits of a home-based exercise intervention," Supportive Care in Cancer, vol. 18, no. 10, pp. 1329-1339, 2010.

[179] S. Brand, M. Gerber, J. Beck, M. Hatzinger, U. Pühse, and E. Holsboer-Trachsler, "High exercise levels are related to favorable sleep patterns and psychological functioning in adolescents: a comparison of athletes and controls," Journal of Adolescent Health, vol. 46, no. 2, pp. 133-141, 2010.

[180] K. M. Chen, M. H. Chen, M. H. Lin, J. T. Fan, H. S. Lin, and C. H. Li, "Effects of yoga on sleep quality and depression in elders in assisted living facilities," The Journal of Nursing Research, vol. 18, no. 1, pp. 53-61, 2010.

[181] J. K. Payne, J. Held, J. Thorpe, and H. Shaw, "Effect of exercise on biomarkers, fatigue, sleep disturbances, and depressive symptoms in older women with breast cancer receiving hormonal therapy," Oncology Nursing Forum, vol. 35, no. 4, pp. 635-642, 2008.

[182] K. J. Reid, K. G. Baron, B. Lu, E. Naylor, L. Wolfe, and P. C. Zee, "Aerobic exercise improves self-reported sleep and quality of life in older adults with insomnia," Sleep Medicine, vol. 11, no. 9, pp. 934-940, 2010.

[183] F. Tentori, S. J. Elder, J. Thumma et al., "Physical exercise among participants in the Dialysis Outcomes and Practice Patterns Study (DOPPS): correlates and associated outcomes," Nephrology Dialysis Transplantation, vol. 25, no. 9, pp. 3050-3062, 2010.

[184] W. Wang, M. Sawada, Y. Noriyama et al., "Tai Chi exercise versus rehabilitation for the elderly with cerebral vascular disorder: a single-blinded randomized controlled trial," Psychogeriatrics, vol. 10, no. 3, pp. 160-166, 2010.

[185] D. Kadetoff and E. Kosek, "The effects of static muscular contraction on blood pressure, heart rate, pain ratings and pressure pain thresholds in healthy individuals and patients with fibromyalgia," European Journal of Pain, vol. 11, no. 1, pp. 39-47, 2007.

[186] R. Staud, M. E. Robinson, E. E. Weyl, and D. D. Price, "Pain variability in fibromyalgia is related to activity and rest: role of peripheral tissue impulse input," The Journal of Pain, vol. 11, no. 12, pp. 1376-1383, 2010.

[187] C. J. Vierck, R. Staud, D. D. Price, R. L. Cannon, A. P. Mauderli, and A. D. Martin, "The Effect of maximal exercise on temporal summation of second pain (windup)in patients with fibromyalgia syndrome," The Journal of Pain, vol. 2, no. 6, pp. 334-344, 2001.

[188] K. D. Jones and G. L. Liptan, "Exercise interventions in fibromyalgia: clinical applications from the evidence," Rheumatic Disease Clinics of North America, vol. 35, no. 2, pp. 373-391, 2009.

[189] M. D. Delp, "Differential effects of training on the control of skeletal muscle perfusion," Medicine and Science in Sports and Exercise, vol. 30, no. 3, pp. 361-374, 1998.

[190] A. T. White, A. R. Light, R. W. Hughen et al., "Severity of symptom flare after moderate exercise is linked to cytokine activity in chronic fatigue syndrome," Psychophysiology, vol. 47, no. 4, pp. 615-624, 2010. 
[191] C. J. Woolf, "Pain: moving from symptom control toward mechanism-specific pharmacologic management," Annals of Internal Medicine, vol. 140, no. 6, pp. 441-451, 2004.

[192] B. K. Pedersen and B. Saltin, "Evidence for prescribing exercise as therapy in chronic disease," Scandinavian Journal of Medicine and Science in Sports, vol. 16, supplement 1, pp. 3-63, 2006. 


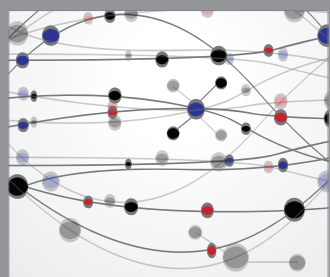

The Scientific World Journal
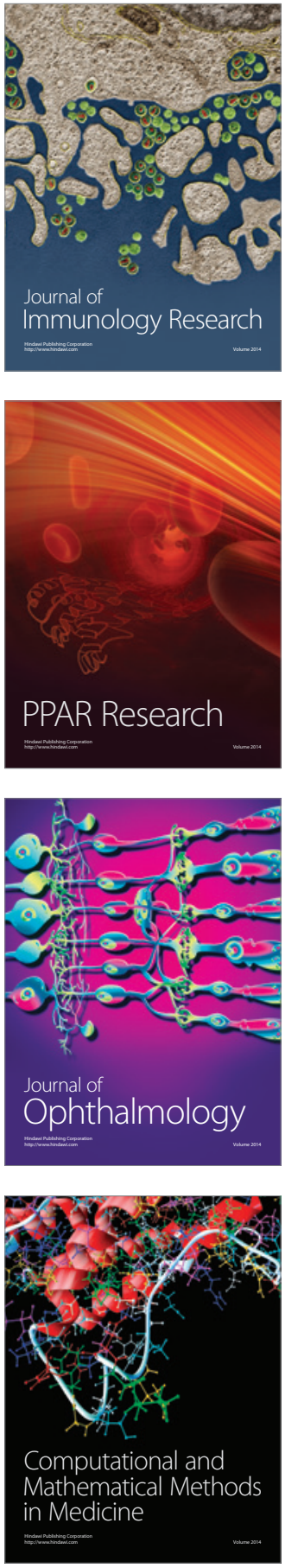

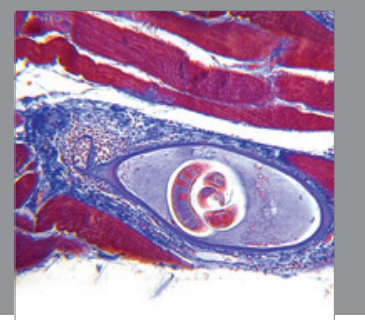

Gastroenterology

Research and Practice
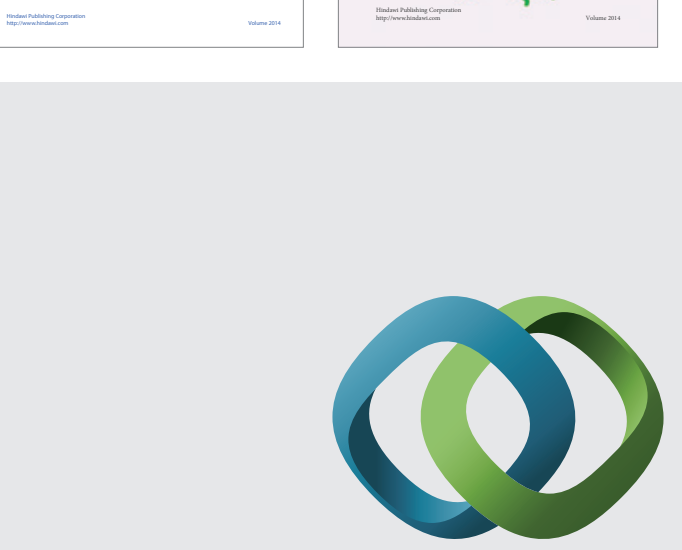

\section{Hindawi}

Submit your manuscripts at

http://www.hindawi.com
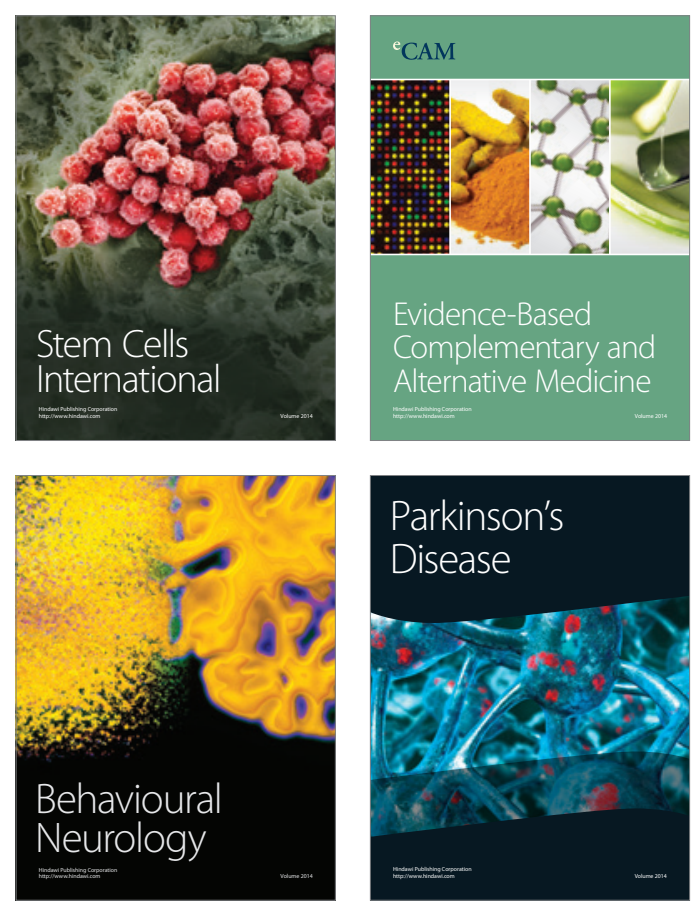

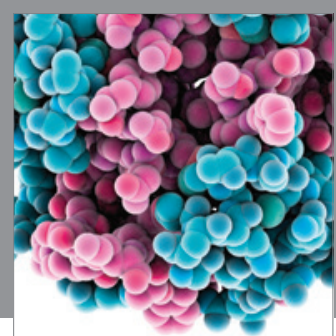

Journal of
Diabetes Research

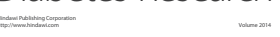

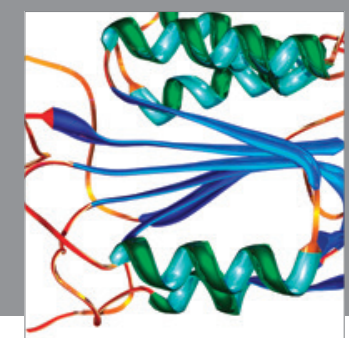

Disease Markers
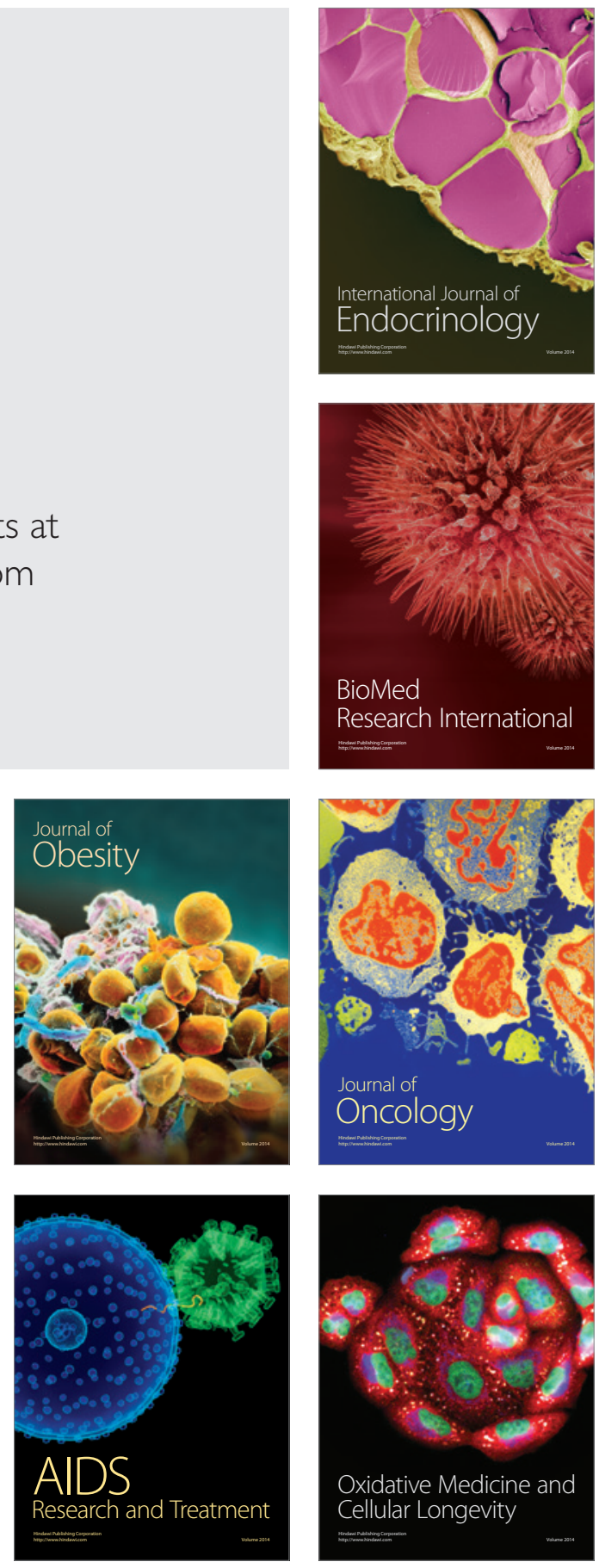